\title{
The dynamics of trade integration and the political value of commitment
}

\author{
By Carsten Hefeker ${ }^{\star}$ and Daniel Gros $\uparrow$ \\ ${ }^{\star}$ WWZ, University of Basel, Petersgraben 51, 4003 Basel, Switzerland \\ $\uparrow$ Centre for European Policy Studies, Brussels, Belgium
}

\begin{abstract}
The paper analyzes the importance of credible institutions in the process of trade liberalization. It combines aspects of credible policy announcements with adjustment costs. We show that if industries' profits are subject to adjustment costs, a dynamic link between periods arises that creates constituencies for a non-discretionary trade policy regime. The conditions for a government to select such an institutional solution are derived.
\end{abstract}

\section{Introduction}

What incentives does a politically self-interested government have to enter a binding trade agreement as opposed to a more flexible arrangement with escape clauses? Facing an ongoing process of trade liberalization among developed and developing countries today, the question arises why and how trade liberalization has become more formalized over time. In contrast to GATT (and its successor the WTO) which provided escape clauses, more and more bilateral trade agreements with rigid rules are signed. GATT was always a rather loose arrangement, its coverage being hampered by exceptions and escape clauses. In addition, tariffs were increasingly substituted by non-tariff barriers that were and still are outside the GATT/WTO domain (Bhagwati, 1988). Therefore, it has always been less important than more restricted arrangements (Irwin, 1995). In marked contrast to this is the process of deepening integration among European countries, moving from the European Coal and Steel Community to the European Union. The fact that other trading blocs in East Asia, the Pacific, and the Western Hemisphere are emerging as well suggests that more formal institutions that make free trade non-contingent and committed become increasingly important (see Fernández, 1997). So why do governments constrain their discretion by choosing such a solution and what is the political value of commitments in trade integration? How does this value differ across countries and states of nature?

To answer this question, the present paper draws on several strands in the current literature on trade policy, combining them in a novel way. First of all, we point out a largely neglected fact in international trade, namely that trade is often path-dependent, i.e. the level of trade today has an influence on the level of trade tomorrow. As Eichengreen and Irwin (1996) argue, once producers, because 
of earlier colonialism, migration, or other (passing) historical reason, have set up market-specific sales, distribution, and service networks in their export markets, this further shapes trade relations. These sunk costs are associated with persistent increases in the trading volume, even if later developments would predict a subsequent fall in the level of trade.

We go beyond their evidence in two regards. First, we explictly model the investment decision of the export industry and show how this can have an important influence on the trade policy of a politically self-interested government. In the presence of adjustment costs exporting industries have a strong interest in ongoing trade liberalization and deepening integration and push the government in that direction. We secondly argue that market penetrating investments not only account for hysteresis but lead to further integration, thus exhibiting a dynamic of increasing integration. ${ }^{1}$ This effect is most visible in the process of European integration. Whereas in the beginning the few member states still traded mainly with third countries, nowadays member states trade about a half more than one could expect from standard gravity models (Frankel and Wei, 1995).

The second class of literature we build on addresses the recent move of governments to free trade from an endogenous political economy perspective. While the literature has usually been concerned with explaining protection (see Hillman, 1989; Rodrik, 1995, for surveys), recently attention has turned to explaining the move to free trade agreements, albeit in a static setting. Grossman and Helpman (1995) examined the political process in one country that generates free trade agreements as the outcome of an interaction between import competing and export oriented industries and the interests of consumers. Hillman et al. (1995) have interpreted free trade as a mutual exchange of market access between two large countries that benefit exporting industries. Free trade agreeements are pursued for domestic distributional reasons and international agreements serve to internalize terms-of-trade effects (see also Bagwell and Staiger, 1996). Our model also considers the influence of two competing industries and consumers but abstracts from terms-of-trade effects. It adds instead a dynamic interaction where the government's policy credibility is an important issue.

Thus, we draw on a third literature that points out the importance of credible commitments by governments in trade policy. Staiger and Tabellini (1987) and Tornell (1989), among others, have shown that non-credible trade policy announcements have an influence on private resource allocation. Even if welfare maximizing governments promise free trade because it is ex-ante optimal, they will ex-post introduce trade barriers to aid industries that are adversely hit by price shocks. Because factors of production cannot costlessly reallocate between sectors,

\footnotetext{
${ }^{1}$ This argument resembles the 'neo-functionalist' approach in political science (Haas, 1958), which maintains that once countries have chosen to integrate one policy area, there is intrinsic pressure to continue with other policy areas. If no further integration is forthcoming, there is the risk that the achieved level of integration is not robust. This is also known as the bicycle theory of integration (see Staiger, 1995).
} 
it is welfare increasing in those models to grant them protection to make adjustment easier. Since private agents know the government's reaction function they will undertake too little adjustment to economic shocks, speculating on government support via protection. The allocation of resources is consequently distorted. Whereas these authors assume benevolent governments, Maggi and RodríguezClare (1998) have recently analyzed the incentives of politically motivated governments to use free trade agreements to commit themselves vis-à-vis interest groups. In both cases, however, free trade is chosen unilaterally. ${ }^{2}$

In our particular model, we use a similar argument in an endogenous policy setting with retaliation. We show that there are situations in which the export industry will only invest into foreign markets if the trade policy regime is nondiscretionary. The export industry then has a stake in a non-discretionary trade regime and will try to influence the political process to this end. The government has to trade off a policy commitment with (relatively) free trade and higher profits for the export industry against the possibility of being able to change trade policy should the need to protect the import competing industry arise. When deciding on the choice of the trade policy regime, the government weighs the interests of opposing industries and consumers.

Finally, our paper is implicitly related to the recent political economic debate on bilateralism and regionalism in trade policy (see e.g. Bagwell and Staiger, 1996; Bhagwati, 1993; Ethier, 1998; Levy, 1997). Bilateral trade agreements, that are mostly regionally concentrated, go further than mulilateral agreements under the GATT/WTO umbrella. In the logic of our paper regional free trade agreements arise because the large and heterogenous number of countries in a multilateral setting makes negotiations too difficult to conduct, implement, and control, thus undermining their credibility (Krugman, 1993). As Ethier (1998) points out, smaller groups of countries are better able to consent to far reaching trade agreements that are not subject to escape clauses.

\section{The model}

We use a partial equilibrium model that captures only the economic effects of trade policy. Trade policy is only part of a government's political agenda. Depending on the size of the economy under consideration, trade policy can be of very little relevance for the overall political position of the government. Since we are concerned with decision making in this area, however, we isolate the effects of this policy from the overall political performance and position of the government. Interest groups and consumers only influence policy in this domain if they have

\footnotetext{
${ }^{2}$ There is also a large literature in constitutional political economy that addresses the consensus of individuals to choose constitutional solutions to rule out distributional conflicts in the policy arena (Buchanan, 1987). Here, however, the choice of commitment is contested and not made behind a veil of ignorance. See Dixit (1996) for a recent discussion of this point.
} 
an interest in trade policy, be it as producers or consumers; stakes in other policy areas are excluded. All indivduals are risk-neutral.

We consider two tradable goods producing sectors. One sector is producing exports and the other sector is import competing. Only the import competing good is domestically consumed. Export and import goods are imperfect substitutes to their foreign competitors. Capital in both sectors is specific while labor is perfectly mobile so that wages are equalized across sectors and have the value $c$ per unit of output.

Demand for the domestically produced import competing good at time $t$ is given as

$$
m_{t}=\beta-\left(p_{t}^{m}-\left(p_{W, t}^{m}+2\left(\tau_{t}-\varepsilon_{t}\right)\right)\right)
$$

It is a positive function of a constant parameter $\beta$ reflecting the preference domestic consumers have for the domestic good, and depends negatively on the difference between the home price for the good $p_{t}^{m}$ and the world market price for the foreign substitute $p_{W, t}^{m}$ on which the government may additionally levy an import tariff $\tau$. Since, in period two, the import competing industry faces the risk of an exogenous shock to the world market price of the competing product $\varepsilon$ with the ex-ante probability of $Q$ (known to both industries and the government), the tariff may be increased to mitigate this negative effect. (The factor 2 is for mathematical convenience only and has no economic importance.) Thus, the import industry has an interest in a discretionary trade policy regime that allows for increasing trade barriers should such a shock occur.

Foreign demand for the export good is

$$
x_{t}=\alpha-\left(\left(p_{t}^{x}+2 \theta \tau_{t}\right)-p_{W}^{x}\right)
$$

where $\alpha$ is the autonomous foreign demand for the domestic export good. We assume that the export industry faces potential trade barriers that are connected to the home rate of protection $\tau$ by the factor $\theta$. We assume that the foreign governments retaliates for a domestic tariff increase to a degree of $\theta \in(0, \infty)$. This reflects the fact that in reality protectionist trade policy even by small countries usually triggers retaliation from foreign countries (Gould and Woodbridge, 1998; Staiger, 1995). ${ }^{3}$ Retaliation relates the profits of the export industry to domestic trade policy. In what follows we only consider tariffs and disregard other kinds of trade barriers, such as VERs and quotas. Since we are concerned with trade regimes and not the choice of a particular instrument of protection, we make this simplifying assumption. ${ }^{4}$ The rate of protection can be set cooperatively or non-cooperatively among countries $\tau_{t} \in\left\{\tau^{C}, \tau^{N}\right\}$. We specify these values below.

The profit functions of the two industries are functions of the domestic prices of the two goods and the constant marginal cost of labor $c$

\footnotetext{
${ }^{3}$ For the endogenous consideration of countries to use retaliation or not, see Gould and Woodbridge (1998).

${ }^{4}$ There is a large literature on the political choice of particular instruments. See Hillman (1989) or Rodrik (1995) for a review of the theoretical literature, and Bhagwati (1988) for a discussion of the relative importance of the different instruments.
} 


$$
\pi_{t}^{x}=\left[p_{t}^{x}-c+2 \xi \phi\right] x_{t}-\xi F(\phi) \quad \text { with } \xi= \begin{cases}0, & \text { for } \phi=0 \\ 1, & \text { for } \phi>0\end{cases}
$$

and

$$
\pi_{t}^{m}=\left[p_{t}^{m}-c\right] m_{t}
$$

respectively. In the first period the export industry, described by eq. 3 , has the possibility to invest into access to the foreign market that increases its profits. One can think about these as setting up market specific sales, distribution, and service networks, as acquiring a better knowledge of the foreign market, or finding and establishing a close relation with reliable and trustworthy foreign partners that all lower the costs of penetrating the foreign market. ${ }^{5}$ Even though firms are able to export without making this additional investment, their profits and the volume of trade will be lower if they do not invest. These investment costs $F(\phi)$ are sunk in period 1 and secure higher profits $\phi$ per unit of output in both periods. ${ }^{6}$ Finally, we assume that restrictions in the ability to borrow prevent that only one domestic firm exports and that it invests in all possible foreign markets. Therefore, there is a tendency for deeper integration with only a few countries.

In the first period, both industries have the option to lobby for their preferred trade policy regime. The government can either choose a discretionary regime, like GATT, which preserves the option to increase trade barriers if the need should arise via its escape clauses. Or it could credibly commit to cooperative trade policy by entering a more rigid free trade agreements in the nature of the European Union. This second option precludes the government raising trade barriers to compensate the import competing industry for the external price shock. Both industries will try to influence the policy regime according to their own interests and reward the government by lobbying contributions.

By making a commitment the present government could also bind any possible successor government which might be more or less inclined to free trade. In our model, however, such ideological differences between governments are excluded. Instead, we impose the same utility function on all governments so that changes in government are irrelevant. There is hence no role for competition between parties and strategic incentives to bind one's successor. ${ }^{7}$

The assumption that firms lobby only in period 1 might seem restrictive but makes sense for the purpose of the present paper because the contested issue is the trade regime, chosen in period 1. If the export industry is not successful, it has no incentive to lobby in period 2 because it is clear that the government will set higher tariff rates whenever a price shock to the import competing good occurs. Of course,

\footnotetext{
${ }^{5}$ The importance of these adjustments costs is often discussed in connection with pricing to market behavior (Baldwin, 1988; Kasa, 1992).

${ }^{6}$ We do not allow for the possibility that the export industry can wait until the second period before it makes its investment decision. This reflects that whenever the export industry invests, it looks forward to at least another period because investment into the foreign market is always important for more than one period. Assuming only three periods is the easiest way to model this fact.

${ }^{7}$ We are grateful to one referee for raising this issue.
} 
the export industry might try to influence the level of tariff that is chosen under the discretionary trade regime. But since we are concerned with the regime instead of the level of tariffs, we abstract from this complication. Likewise, if the government enters a committed trade regime the import industry has no reason to lobby because the government is not able to change the agreed tariff rate.

The objective function of the government is given as

$$
G(\tau, \phi, \varepsilon)_{t}=\sum_{i} \Lambda^{i}+a \Omega_{t} \quad i=x, m
$$

with

$$
\Omega_{t}=\pi_{t}^{x}+\pi_{t}^{m}+c\left(x_{t}^{*}+m_{t}^{*}\right)+\tau_{t}\left(M_{t}\left(m_{t}^{*}\right)-\delta \tau_{t}\right)
$$

which is similar to the formulation chosen by Brainard and Verdier (1997). The government cares for political contributions in the form of lobbying expenditures it collects $\Lambda^{x}+\Lambda^{m}$ and the utility of domestic industries and consumers $\Omega{ }^{8} \Omega$ reflects efforts to maximize political support where the relevant groups in a society enter with relative weights that capture their political importance or influence (see Hillman and Ursprung, 1996). It is comprised of the profits of the two industries $\pi_{t}^{x}$ and $\pi_{t}^{m}$, the income of workers from the production in the two industries $c\left(x_{t}^{*}+m_{t}^{*}\right)$, the revenue from trade policy $\tau M_{t}\left(m_{t}^{*}\right)$ and the aversion of consumers to higher import prices $\delta \tau_{t}^{2}$. The relative weight of these influences vis-à-vis the lobbying-revenue motive is $a \in(0, \infty)$. To determine tariff revenue, let exogenous demand for the foreign import good be given as $M_{t}(\varepsilon, \tau)=\gamma-\left(\left(p_{W, t}^{m}+2(\tau-\varepsilon)\right)-p_{t}^{m}\right) .{ }^{9}$ By using eq. (1), imports can then be calculated as $M_{t}=\gamma+\beta-m_{t}^{*}$, where $m_{t}^{*}$ denotes domestic production, as determined below.

\subsection{The time structure of the game}

Time is divided in three periods, and we assume for simplicity that the common discount factor is one. We begin with a period 0 in which trade policy is set at a negotiated level $\tau^{C} \geq 0$. The maximization of $\Omega$ in (5) with respect to trade policy in period 0 would result in $\tau_{0}^{*}=(\theta \bar{x}-\bar{m}-(c(1-\theta)+\gamma+\beta-\bar{m}) / 2) /\left(\theta^{2}-\delta\right)$. However, in what follows we assume that $\tau^{C} \in\left[0, \tau_{0}^{*}\right]$ and thus take the level of trade barriers in period 0 as exogenous. This assumption reflects the fact that political events can be important for trade policy. A tariff could either be imposed on the country from abroad, as in Europe after World War II where the US induced European recipients of Marshall plan aid to lower tariff barriers among themselves, or be the result of bilateral or multilateral trade negotiations, reflecting some compromise. So the country may either be able to set its preferred tariff rate

\footnotetext{
${ }^{8}$ Note that the assumption that an industry is lobbying implies that the individual firms in a given industry are able to solve their collective action problem. One reason could be that firms are organized in business associations.

${ }^{9}$ The inclusion of tariff revenues in the political support function implies that the government cannot appropriate those for private use. They are either redistributed to consumers or used to lower taxation. Therefore, tariff revenues increase political support.
} 
or be restricted in the choice of its tariff rate. How $\tau^{C}$ is actually determined is not important for the following analysis; it is however important that exogenous events can create a dynamic with respect to the preferred trade regime.

In period 1 the government has to make its choice about the trade policy regime for the rest of the time under consideration, without knowing with certainty the developments in period 2. This restriction to three periods is somewhat artificial but allows for successive rounds of this game. One might assume that periodically the government has to decide upon entering a regime or changing a given regime. Events then develop as follows: (i) in period 1 firms lobby; (ii) the government decides to enter a discretionary or non-discretionary trade policy regime and collects lobbying contributions; (iii) the export industry decides whether to make its investment; (iv) production in both industries takes place and profits are realized; ( $\mathrm{v}$ ) in period 2 the external terms-of-trade shock is realized or not; (vi) if so, the government reacts with a higher tariff in the discretionary regime; (vii) the foreign country retaliates; and (viii) production in both industries takes place and profits are realized.

The chosen time structure results in the following strategic interactions between the industries and the government. The government is Stackelberg-leader to the actions of the second period. It knows the profit and cost function of both industries and can thus take their equilibrium output (as a function of trade policy) into account when setting its trade policy. The two industries move simultaneously. We also assume, as in Grossman and Helpman (1995), that the lobbies promise to make a certain contribution to an incumbent if their preferred policy is chosen and that they pay this promised sum only if their preferred result is implemented. ${ }^{10}$ The lobby whose choice is not implemented does not contribute. To derive the subgame perfect Nash equilibrium of this game, we begin by looking at production decisions in the second period.

\subsection{The second period}

Imagine that in period 2 the world price of the import competing good suffers from a positive supply shock that lowers the world market price of $m$ by $\varepsilon$. To counter this negative effect for profits and employment in the import competing industry, the government can decide to set an import tariff for this good $\tau^{N}>\tau^{C}$ to protect the import competing industry. The motive for doing this via trade policy is the absence of other, less distorting, instruments of income redistribution. This includes as well the assumption that compensation across groups is impossible.

Domestic demand directed towards the import competing industry is given in (1) with $\tau_{t} \in\left\{\tau^{C}, \tau^{N}\right\}$. The export firm is in contrast faced with (2) with $\theta \tau_{t}$. Given

\footnotetext{
${ }^{10}$ An alternative specification would introduce competing politicians where lobbies support the candidate with their preferred platform to improve her election probability. See Hillman (1989) or Rodrik (1995) for alternative model specifications.
} 
this, the two firms determine their production by maximizing (3) and (4), using (1) and (2) respectively. The second period output of the export industry is given as

$$
x_{2}^{*}=\frac{\left(\alpha+p_{W}^{x}-c\right)-2(\theta \tau-\xi \phi)}{2} \equiv \bar{x}+\xi \phi-\theta \tau
$$

where $\xi \in\{0,1\}$ depending on whether the investment has been made in period 1 or not, and $\tau \in\left\{\tau^{C}, \tau^{N}\right\}$. The output of the import competing industry is given as

$$
m_{2}^{*}=\frac{\left(\beta+p_{W}^{m}-c\right)-2\left(\varepsilon_{i}-\tau\right)}{2} \equiv \bar{m}+\tau-\varepsilon
$$

with $\varepsilon \in\{0,1\}$ and $\tau \in\left\{\tau^{C}, \tau^{N}\right\}$.

If the price shock occurs in the discretionary regime, the government will set its trade policy so as to fulfill the condition $\partial \Omega_{2} / \partial \tau_{2}=0$ which determines the optimal trade restriction as $\tau_{2}^{*}=(\theta(\bar{x}+\phi)-\bar{m}+\varepsilon-(c(1-\theta)+\gamma+\beta-\bar{m}) / 2) /$ $\left(\theta^{2}-\delta\right)$. However, given our assumption about the exogenous setting of the cooperative tariff, we analogously define

$$
\tau^{N} \equiv \tau^{C}+\Delta \tau(\phi)
$$

The importance of a binding free trade agreement follows because the government has no other mechanism to credibly commit to set trade policy cooperatively if the negative shock on the import sector occurs. Any promise to do so is simply not time-consistent. The rational private sector thus knows that in the case of $\varepsilon>0$ trade policy will change by $\Delta \tau(\phi)$ in the discretionary regime. Notice that the change in trade policy $\Delta \tau$ is a function of $\phi$. With investment into the foreign market, the profits of the export industry are higher than otherwise and therefore the government can afford to choose a policy that benefits the import competing industry more. We will return to this effect below.

In the next step, we analyze how trade policy in period 2 affects the decisions of the industries and the government in period 1 . The value of a given trade policy for the industries is determined by the influence it has on the profits. Hence, at the margin each lobby's outlay to influence the policy choice is equal to the value of the policy measure, i.e. to its influence on profits.

\section{The export industry's investment decision}

Before we can analyze the government's choice of the trade policy regime we have to derive the stakes of the industries in a particular trade regime. For the export industry, the stakes differ according to whether its has made the investment into the foreign market or not since this influences the profits exporting firms can derive from the regime choice. We thus have to see under which conditions it will make this investment. We begin with the non-discretionary trade policy regime.

\subsection{Investment under commitment}

The export industry will make the investment in the foreign market whenever the expected profits over the relevant time horizon will be larger if the investment is made than if it is not made. The condition is thus 


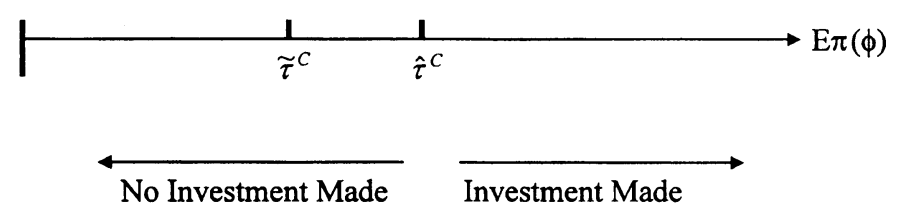

Fig. 1

$$
\sum_{t} \pi_{t}^{x, C}\left(\phi, \tau^{C}\right)-F(\phi)>\sum_{t} \pi_{t}^{x, C}\left(0, \tau^{C}\right) \quad t=1,2
$$

where 0 denotes the case when no investment is made. Using (3) in (9) one sees that the export industry will invest as long as

$$
\phi+2 \bar{x}-\frac{F(\phi)}{2 \phi}-2 \theta \tau^{C} \equiv \tilde{I}-2 \theta \tau^{C}>0
$$

is fulfilled, which implies that there is a critical level of costs for this investment $F(\phi)$ that must not be surpassed to keep the investment profitable. If this condition $\tilde{I}>0$ is fulfilled, there is in addition a critical value of cooperative trade policy $\hat{\tau}^{C}$ below that the investment into the foreign market is made by the export industry. Exogenous shocks to this cooperative rate of trade policy in perido 0 can trigger a change in the equilibrium in period 1 that is totally independent from any other consideration like those that follow in the next sections. We summarize this result as our

Proposition 1 Assume a credible non-discretionary trade policy regime, where an investment by the export industry into the foreign market is per se profitable, $\tilde{I}>0$, so that it only depends on the level of tariffs. Then, everything else equal, an exogenous shock in period 0 to the cooperative trade policy from

$$
\tilde{\tau}^{C}>\frac{\tilde{I}}{2 \theta} \text { to } \hat{\tau}^{C}<\frac{\tilde{I}}{2 \theta}
$$

can trigger this investment into the foreign market and a change in the export industry's output.

The idea is illustrated in Fig. 1. Imagine an initial value of $\tilde{\tau}^{C}>\hat{\tau}^{C}$ which is large enough to block the investment from being made. If then an exogenous event lowers $\tau^{C}$ to $\hat{\tau}^{C}$, the export industry, everything else equal, will sink the investment costs.

This Proposition covers shifts in trade policy due to successive rounds of GATT negotiations or the process of European integration which started with a political free trade shock after the second world war. These changes can set in motion a new round of political interaction between the industries and the government in a given country. ${ }^{11}$ An exogenous shock to the tariff level can lead to trade that is larger than would result from the initial shock because it makes market penetrating investment

\footnotetext{
${ }^{11}$ Baldwin (1993) uses a similar argument for the widening of trade blocs instead of deepening that is considered here.
} 
profitable if the trade regime is non-discretionary. The initial shock thus also creates an interest by the export industry in commitment. A dynamic process of further liberalization becomes attractive, as the next section will show.

In what follows we assume additionally that $\tilde{I}-2 \theta \tau^{C} \equiv \hat{I}>0$ to make the problem interesting. Otherwise, the export industry would not invest into the foreign market and this would clearly erode its incentive to have a commitment in trade policy. The export industry would still have an interest in trade policy per se and the level of tariffs but not in the regime because it could always optimally adjust its output.

\subsection{Investment under discretion}

We now derive the investment decision for the case of policy discretion. The export industry will only sink the costs of investing into the foreign market if

$$
E \sum_{t} \pi_{t}^{x, D}(\phi, \tau)-F(\phi)>E \sum_{t} \pi_{t}^{x, D}(0, \tau) \quad t=1,2, \tau=\left\{\tau^{C}, \tau^{N}\right\}
$$

where $E$ denotes the expectations operator. Given the exogenous probability that trade policy changes, the export industry's profits in period 2 are

$$
E \pi^{x, D}(i)=\left\{\begin{array}{ll}
\pi^{x}\left(i, \theta \tau^{N}\right) & \text { with probability } Q \\
\pi^{x}\left(i, \theta \tau^{C}\right) & \text { with probability }(1-Q)
\end{array} \quad i=\phi, 0\right.
$$

This leads directly to our second proposition.

Proposition 2 Assume the discretionary trade policy regime. Then there exists for all $\theta \Delta \tau>0$ a critical probability $\hat{Q}$ for the shift to a non-cooperative trade regime in period 2 above which no investment $\phi$ in the foreign market will be made, even if the investment would be profitable under commitment.

This can be seen by adding up the two possible outcomes under discretion and comparing the cases of investment and no-investment. We then arrive at $\hat{I}-Q \theta \Delta \tau \geq 0$, which defines a critical $\hat{Q}$ above which no investment will be made in the discretionary regime. (We assume that no investment will be made at $Q=\hat{Q}$.) The condition can also be seen with the help of Fig. 2. Thus for all $\theta \Delta \tau>0$ the investment decision of the export industry is distorted. The mere possibility that in the second period a shift to non-cooperative trade policy might occur will raise the barrier to investment for the export industry. There is therefore a connection between the two periods and we have:

Proposition 3 In the presence of adjustment costs, exports in the second period are a function of exports in the first period. If the market penetrating investment by the export industry is sunk in the first period, output and profits in periods 1 and 2 are higher. In this case the export industry prefers a non-discretionary trade policy regime.

This Proposition establishes the interest of the export industry in an institutional solution to trade policy that ensures a cooperative trade policy across all states of 


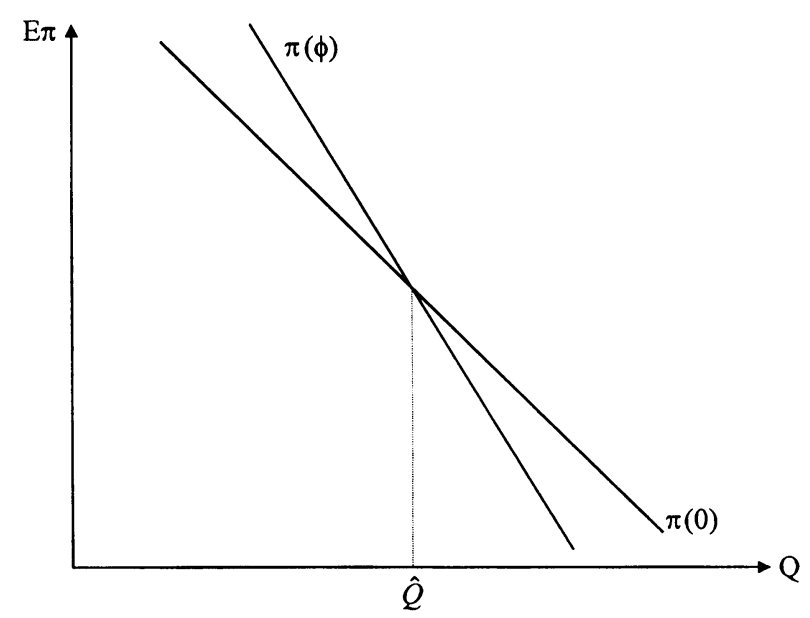

Fig. 2

nature. At the same time it is clear that such a solution can only come at the costs of the import industry. Thus both have a stake in the trade policy regime and will try to influence the government's decision.

\section{The political value of commitment}

To derive the government's decision to commit to free trade or to rather preserve discretion in trade policy is a straightforward exercise. The government will choose the policy that will realize higher political values in the form of lobbying contributions and political support

$$
E \sum_{t} G_{t}^{C}(\phi, \tau, \varepsilon)>E \sum_{t} G_{t}^{D}(\phi, \tau, \varepsilon) \quad t=1,2
$$

where all variables can take two values $\tau=\left\{\tau^{C}, \tau^{N}\right\}, \phi=\{0, \phi\}$, and $\varepsilon=\{0, \varepsilon\}$. To derive the choice of the government, we have to see how high the lobbying outlays of the two industries for their preferred regime regimes will be in addition to the political support in each case.

\subsection{The import competing industry}

Let us first derive the value of discretion for the import competing industry. That value is determined by the difference

$$
E \sum_{t} \pi_{t}^{m, D}-E \sum_{t} \pi_{t}^{m, C}=\Lambda^{m}
$$

The value of the trade policy decision for the industry is the difference in profits it implies. It is thus willing to contribute not more than the difference in the expected profits under the two regimes to the government. 
The industry knows that with probability Q the shock $\varepsilon$ occurs, whose negative effects can be compensated if the government sets $\tau^{N}$ in the discretionary regime. As profits are higher when tariffs can be increased should the need arise, the value of discretion for that industry is obvious from comparing the expected profits under both regimes. This yields

$$
\Lambda^{m}= \begin{cases}Q\left[\left.2(\bar{m}-\varepsilon) \Delta \tau\right|_{\phi>0}+\left.\Delta \tau^{2}\right|_{\phi>0}\right] & \text { if } Q<\hat{Q} \\ Q\left[\left.2(\bar{m}-\varepsilon) \Delta \tau\right|_{\phi=0}+\left.\Delta \tau^{2}\right|_{\phi=0}\right] & \text { if } Q \geq \hat{Q}\end{cases}
$$

where $\Delta \tau^{2} \equiv \tau^{N^{2}}-\tau^{C^{2}}$. Clearly, an increase in the probability of a price shock will raise lobbying contributions, as will the prospective size of the tariff increase. Also, the import competing industry will adjust its lobbying contributions if the export industry has made its investment into the foreign market. It is not clear, a priori, in which case lobbying contributions are larger because $Q$ and $\Delta \tau(\phi)$ have opposing influences.

\subsection{The export industry}

The value of commitment for the export industry as well is a function of $\hat{Q}$. Two cases can be distinguished, $Q<\hat{Q}$ when the firms will always sink the investment costs into the foreign market, and $Q \geq \hat{Q}$ when the value of commitment is heightened for the export industry, because only under commitment the profit increasing investment in the foreign market will be made. We therefore have

$$
\Lambda^{x}= \begin{cases}Q \theta\left[\left.2(\bar{x}+\phi) \Delta \tau\right|_{\phi>0}-\left.\theta \Delta \tau^{2}\right|_{\phi>0}\right] & \text { if } Q<\hat{Q} \\ \hat{I}+Q \theta\left[\left.2 \bar{x} \Delta \tau\right|_{\phi=0}-\left.\theta \Delta \tau^{2}\right|_{\phi=0}\right] & \text { if } Q \geq \hat{Q}\end{cases}
$$

The lobbying contributions are higher if $Q \geq \hat{Q}$ than otherwise if

$$
\hat{I}>Q \theta\left[2 \bar{x}\left(\left.\Delta \tau\right|_{\phi>0}-\left.\Delta \tau\right|_{\phi=0}\right)-\theta\left(\left.\Delta \tau^{2}\right|_{\phi>0}-\left.\Delta \tau^{2}\right|_{\phi=0}\right)+\left.2 \phi \Delta \tau\right|_{\phi>0}\right]
$$

which means that the loss from the forgone investment in the foreign market given a high probability of $\varepsilon$ must be large enough. Otherwise, it would not pay for the export industry to make any attempts at influencing the choice of the trade policy regime.

\subsection{The government}

To determine the government's choice, we begin by isolating the added utilities of all agents in the economy, consumers, and industries, for the relevant cases before we add the lobbying contributions. This part of the government's utility function, summarized in $\Omega$, is the political support function that weighs the utilities of the industries and consumers. Political support as well is a function of $\hat{Q}$ because it influences the investment decision of the export industry and will hence determine the optimal output of the export industry which enters national welfare via the employment effect. Clearly, under commitment $\Omega$ is not varying because in this case the investment is always made by the export industry, and we have 


$$
\begin{aligned}
E \Omega^{C}= & 2 \pi^{x}\left(\phi, \theta \tau^{C}\right)-F(\phi)-\Lambda^{x} \\
& +\pi^{m}\left(\tau^{C}\right)+Q \pi^{m}\left(\varepsilon, \tau^{C}\right)+(1-Q) \pi^{m}\left(\tau^{C}\right) \\
& +c\left[2 x\left(\phi, \tau^{C}\right)+m\left(\tau^{C}\right)+Q m\left(\varepsilon, \tau^{C}\right)+(1-Q) m\left(\tau^{C}\right)\right] \\
& +\left[M\left(\tau^{C}\right)+Q M\left(\varepsilon, \tau^{C}\right)+(1-Q) M\left(\tau^{C}\right)-2 \delta \tau^{C}\right] \tau^{C}
\end{aligned}
$$

where the net-imports of the import competing goods $M($.$) and thus the tariff$ revenues vary as a function of the exogenous shock. Profits and output are secure for the export industry, as well as the consumers' loss $\delta \tau^{2}$. The import competing industry however is negatively affected by $\varepsilon$ with probability $Q$. In addition, the export industry has to spend $\Lambda^{x}$ for lobbying. While $\Omega$ is invariant under commitment, under discretion we have to make a differentiation because $Q$ determines whether the investment $\phi$ is sunk or not.

4.3.1 $Q<\hat{Q}$ If the probability for a shock to the world market price of the import competing good is below the critical value, the export industry always makes its investment, since $\hat{I}>0$ by assumption. In this case political support is

$$
\begin{aligned}
\left.E \Omega^{D}\right|_{Q<\hat{Q}}= & \pi^{x}\left(\phi, \theta \tau^{C}\right)-F(\phi)+Q \pi^{x}\left(\phi, \theta \tau^{N}\right)+(1-Q) \pi^{x}\left(\phi, \theta \tau^{C}\right) \\
& +\pi^{m}\left(\tau^{C}\right)+Q \pi^{m}\left(\varepsilon, \tau^{N}\right)+(1-Q) \pi^{m}\left(\tau^{C}\right)-\Lambda^{m} \\
& +c\left[x\left(\phi, \tau^{C}\right)+m\left(\tau^{C}\right)+Q\left(x\left(\phi, \theta \tau^{N}\right)+m\left(\varepsilon, \tau^{N}\right)\right)\right. \\
& \left.+(1-Q)\left(x\left(\phi, \tau^{C}\right)+m\left(\tau^{C}\right)\right)\right] \\
& +\left(M\left(\tau^{C}\right)-\delta \tau^{C}\right) \tau^{C}+Q\left(M\left(\varepsilon, \tau^{C}\right)-\delta \tau^{N}\right) \tau^{N} \\
& +(1-Q)\left(M\left(\tau^{C}\right)-\delta \tau^{C}\right) \tau^{C}
\end{aligned}
$$

The government will choose commitment over discretion if

$$
\Lambda^{x}+a \sum_{t} \Omega_{t}^{C}=E \sum_{t} G_{t}^{C}>E \sum_{t} G_{t}^{D}=\Lambda^{m}+a \sum_{t} \Omega_{t}^{D} \quad t=1,2
$$

This condition is fulfilled if and only if

$$
\begin{aligned}
& Q\left(\left.\Delta \tau\right|_{\phi>0} 2[\theta(\bar{x}+\phi)-(\bar{m}-\varepsilon)]\right) \\
& \quad>Q\left(\left.\Delta \tau^{2}\right|_{\phi>0}\left[\left(1+\theta^{2}\right)-a(1+\delta)\right]+\left.a \Delta \tau\right|_{\phi>0}[(1-\theta) c+M(\varepsilon)]\right)
\end{aligned}
$$

which can be seen by using (14) and (15), and (12) and (13) in (16). The left-hand side of this condition reflects the relative size of the sectors, or more precisely, the economic impact a change in the rate of protection would have on the two sectors. Clearly, if the export sector is politically more powerful, the governments tends to implement that sector's preferred choice. The difference in the importance of the two sectors must be larger than the terms on the right-hand side. There, the first term measures the consumers' aversion to higher prices and the difference in the lobbying outlays of the two sectors, while the second term comprises the employment implications of the tariff regimes in both sectors, as well as the 
revenue increase from higher tariffs. The condition thus suggests that countries where the export industry is sufficiently larger than the import competing industry, including the respective employment effects, tend to favor a non-discretionary trade regime.

4.3.2 $Q \geq \hat{Q}$ In this case, more is at stake for both industries because the decision for the export industry to invest is linked to the policy regime chosen. Thus two influences on its profits are at work at the same time. Not only is it important to make sure that the foreign government will not use trade policy, as a reaction to the home government's choice, but discretion will block the investment into the foreign market which will additionally have opportunity costs of forgone profits in periods 1 and 2. Moreover, with $Q$ very high the import industry is almost certain to experience a negative shock to its profits. This will induce it to make more efforts to preserve the instrument of trade policy, as can be seen from eq. (12).

For the government, the added up utilities of the groups in society in this case are

$$
\begin{aligned}
\left.E \Omega^{D}\right|_{Q \geq Q}= & \pi^{x}\left(\theta \tau^{C}\right)+Q \pi^{x}\left(\theta \tau^{N}\right)+(1-Q) \pi^{x}\left(\theta \tau^{C}\right) \\
& +\pi^{m}\left(\tau^{C}\right)+Q \pi^{m}\left(\varepsilon, \tau^{N}\right)+(1-Q) \pi^{m}\left(\tau^{C}\right)-\Lambda^{m} \\
& +c\left[x\left(\tau^{C}\right)+m\left(\tau^{C}\right)+Q\left(x\left(\theta \tau^{N}\right)+m\left(\varepsilon, \tau^{N}\right)\right)\right. \\
& \left.+(1-Q)\left(x\left(\tau^{C}\right)+m\left(\tau^{C}\right)\right)\right] \\
& +\left(M\left(\tau^{C}\right)-\delta \tau^{C}\right) \tau^{C}+Q\left(M\left(\varepsilon, \tau^{N}\right)-\delta \tau^{N}\right) \tau^{N} \\
& +(1-Q)\left(M\left(\tau^{C}\right)-\delta \tau^{C}\right) \tau^{C}
\end{aligned}
$$

By using again (16) and comparing (14) and (15'), and (12) and (13), the following condition has to be met to have the government choose commitment

$$
\begin{aligned}
\hat{I}+a 2 c \phi+ & Q\left(\left.\Delta \tau\right|_{\phi=0} 2[\theta \bar{x}-(\bar{m}-\varepsilon)]\right) \\
& >Q\left(\left.\Delta \tau^{2}\right|_{\phi=0}\left[\left(1+\theta^{2}\right)-a \delta\right]+\left.a \Delta \tau\right|_{\phi=0}[(1-\theta) c+M(\varepsilon)]\right)
\end{aligned}
$$

This condition is very similar to the condition (17). In addition it reflects the higher profits that can be gained by the export industry if it is able to make the foreign investment, which would in this case only occur in the non-discretionary regime, and a component which measures the employment effect of that investment. These terms are contained on the left-hand side, thus supporting the case for commitment. Whether this condition is more likely to be fulfilled than (17) depends on several additional and opposing factors. In $\left(17^{\prime}\right) Q$ is larger than in (17) but the change in the tariff rate is smaller, since $\Delta \tau(0)<\Delta \tau(\phi)$. These two effects offset each other partially. If the effect from investment in the foreign market is very large it is thus more likely that the export industry will prevail in the political process. Economic developments in recent years that have made market penetrating investments more important 
or profitable would clearly raise the export industry's interest in reaping the full benefit from these investments by ruling out a non-cooperative tariff game between governments. In addition, if the chances of retaliation $\theta$ have increased over time, the export industry would additionally like to exclude the dangers of a tariff conflict by having the government enter a non-discretionary trade regime. This, in connection with the fact that tariff negotiations are better conducted in small group of countries, could be one explanation for the trend towards more regionally based as well as more rigid free trade agreements.

\section{Conclusion}

This paper has analyzed the question why trade liberalization proceeds in the form of non-contingent regimes, as reflected in the difference between the tighter European Union and the looser GATT or WTO, and why trade is history dependent. We have shown that one possible explanation can be found in the existence of dynamic effects which link possible states of nature with each other. If the level of trade depends on sunk costs into the foreign market, the export industry has an incentive to make sure that the value of this investment will not be eroded by a shift in the policy regime. As the paper has shown, it can happen that these investment become unprofitable ex-post in which case a forward-looking enterprise would hesitate to make such an investment.

If these costs and forgone profits from discretionary trade regimes have become more important over the last decades this would explain an increased interest the export industry has in an institutional solution. As its stakes from either policy regime have increased, the export industry puts more pressure on the government and this may have brought the political optimizing government to choose a noncontingent trade policy regime. It should, in general, be possible to test this hypothesis empirically by collecting data on investment as well as on the relative importance of the different sectors and the employment effects of trade policy. Of course, another explanation for the widespread move to free trade agreements could be that government preferences have changed over time. True refomers might choose binding agreements to commit their successors in office to a free trade policy. This seems particularly relevant for Eastern European and developing countries (Ethier, 1998).

However, by introducing a largely neglected fact in the literature on international trade policy, namely the influence of dynamic effects, we are able to provide an explanation for the choice of more rigid international trade agreements without relying on preference changes. Although governments will generally prefer discretionary regimes that leave options for policy changes, they may be pushed by interest groups to adopt extreme regimes. While the choice between extreme regimes is a much discussed issue for the choice of international monetary regimes, they are largely neglected for trade regimes. We have shown that extreme regimes are potentially important in trade policy as well. 


\section{Acknowledgements}

This paper has benefited from presentations in workshops in Basel, Bremen and Silvaplana. We are indebted to Jeff Frieden and Erik Jones for introducing us to the political scientist's approach to integration, and to our anonymous referees for comments and suggestions.

\section{References}

Bagwell, K. and Staiger, R.W. (1996). 'Reciprocal Trade Liberalization', Working Paper No. 5488, National Bureau of Economic Research, Cambridge, MA.

Baldwin, R.E. (1988). 'Hysteresis in Import Prices: The Beachhead Effect', American Economic Review, 78, 773-85.

Baldwin, R.E. (1993). 'A Domino Theory of Regionalism', Working Paper No. 4465, National Bureau of Economic Research, Cambridge, MA.

Bhagwati, J. (1988). Protectionism, MIT Press, Cambridge, MA.

Bhagwati, J. (1993). 'Regionalism and Multilateralism: An Overview', in J. de Melo and A. Panagariya (eds), New Dimensions in Regional Integration, Cambridge University Press, Cambridge.

Brainard, L.S. and Verdier, T. (1997). 'The Political Economy of Declining Industries: Senescent Industry Collapse Revisited', Journal of International Economics, 42, 221-37.

Buchanan, J.M. (1987). 'The Constitution of Economic Policy', American Economic Review, 77, 243-50.

Dixit, A.K. (1996). The Making of Economic Policy, MIT Press, Cambridge, MA.

Eichengreen, B. and Irwin, D.A. (1996). 'The Role of History in Bilateral Trade Flows', Working Paper No. 5565, National Bureau of Economic Research, Cambridge, MA.

Ethier, W.J. (1998). 'The New Regionalism', Economic Journal, 108, 1149-61.

Fernández, R. (1997). 'Returns to Regionalism: An Evaluation of Non-Traditional Gains from RTAs', Working Paper No. 5970, National Bureau of Economic Research, Cambridge, MA.

Frankel, J. and Wei, S.-J. (1995). 'European Integration and the Regionalization of World Trade and Currencies: The Economics and the Politics', Working Paper, University of California at Berkeley.

Grossman, G.M. and Helpman, E. (1995). 'The Politics of Free Trade Agreements', American Economic Review, 85, 667-90.

Gould, D.M. and Woodbridge, G.L. (1998). 'The Political Economy of Retaliation, Liberalization and Trade Wars', European Journal of Political Economy, 14, 115-37.

Haas, E.B. (1958). The Uniting of Europe, Stevens and Sons, London.

Hillman, A.L. (1989). The Political Economy of Protection, Harwood Academic Publishers, Chur.

Hillman, A.L., Long, N.V., and Moser, P. (1995). 'Modelling Reciprocal Trade Liberalization', Schweizerische Zeitschrift für Volkswirtschaft und Statistik, 131, 503-15.

Hillman, A.L. and Ursprung, H.W. (1996). 'The Political Economy of Trade Liberalization in the Transition', European Economic Review, 40, 783-94. 


\section{THE DYNAMICS OF TRADE INTEGRATION}

Irwin, D.A. (1995). 'The GATT's Contribution to Economic Recovery in Post-War Western Europe', in B. Eichengreen (ed.), Europe's Post-War Growth, Cambridge University Press, Cambridge.

Kasa, K. (1992). 'Adjustment Costs and Pricing to Market: Theory and Evidence', Journal of International Economics, 32, 1-30.

Krugman, P. (1993). 'Regionalism versus Multilateralism: Analytical Notes', in J. de Melo and A. Panagariya (eds), New Dimensions in Regional Integration, Cambridge University Press, Cambridge.

Levy, P.I. (1997). 'The Political Economy of Free-Trade Agreements', American Economic Review, 87, 506-19.

Maggi, G. and Rodríguez-Clare, A. (1998). 'The Value of Trade Agreements in the Presence of Political Pressures', Journal of Political Economy, 106, 574-601.

Rodrik, D. (1995). 'Political Economy of Trade Policy', in G. Grossman and K. Rogoff (eds), Handbook of International Economics, 3, Elsevier, Amsterdam.

Staiger, R. (1995). 'International Rules and Institutions for Trade Policy', in G. Grossman and K. Rogoff (eds), Handbook of International Economics, 3, Elsevier, Amsterdam.

Staiger, R. and Tabellini, G. (1987). 'Discretionary Trade Policy and Excessive Protection', American Economic Review, 77, 340-48.

Tornell, A. (1991). 'Time Inconsistency of Protectionist Programs', Quarterly Journal of Economics, 104, 963-74. 